\title{
Water transmission properties of a sandy-loam soil estimated with Beerkan runs differing by the infiltration time criterion
}

\author{
Vincenzo Bagarello, Gaetano Caltabellotta, Massimo Iovino* \\ Department of Agricultural, Food and Forest Sciences, University of Palermo, Viale delle Scienze, 90128, Palermo, Italy. \\ * Corresponding author. Tel.: +39 09123897070. E-mail: massimo.iovino@unipa.it
}

\begin{abstract}
The Beerkan method consists of a ponded infiltration experiment from a single ring inserted a small depth into the soil. Fixed, small volumes of water are repeatedly poured into the ring to maintain a quasi-zero head on the soil surface. According to the standard Beerkan infiltration run, a new water volume is poured on the infiltration surface when the previously applied volume has completely infiltrated and the soil surface is entirely exposed to air ( $t_{a}$ criterion). However, water could also be applied when the soil exposition to air begins ( $t_{o}$ criterion) or half the soil surface is exposed to air ( $t_{m}$ criterion). The effect of the infiltration time criterion on determination of the water transmission properties of a sandy-loam soil was tested. As compared with the standard $t_{a}$ criterion, the two alternative criteria $\left(t_{o}, t_{m}\right)$ yielded higher and/or more variable estimates of soil water transmission properties. The saturated soil hydraulic conductivity, $K_{s}$, was the most sensitive property to the infiltration time criterion. However, statistically significant differences for $K_{s}$ were not practically substantial since they did not exceed a factor of 1.7. Infiltration time effects likely occurred due to differences between ponding depth of water, soil water pressure head gradient, air entrapment and soil mechanical disturbance. The standard $t_{a}$ criterion was suggested for performing a Beerkan experiment in the field since it appears to yield the most reliable estimates of a mean value. However, the $t_{o}$ criterion could be considered in dual permeability soils to maintain macropores active. Factors that could appear minor in the context of an experiment can have statistically relevant effects on water transmission properties.
\end{abstract}

Keywords: Soil water transmission properties; Beerkan run; Infiltration time criterion; BEST methodology.

\section{INTRODUCTION}

Soil sorptivity, $S$, and saturated soil hydraulic conductivity, $K_{s}$, allow description of infiltration with physically based models (Iovino et al., 2017; Touma et al., 2007). Sorptivity defines the ability of a soil to conduct water by capillarity and $K_{s}$ represents the maximum rate of water flow due solely to gravity in a completely saturated soil. The relative importance of capillarity over gravity forces during infiltration, the effective mean pore radius and the depth of the wetting front during infiltration can be determined from measurement of $S$ and $K_{s}$ (Ndiaye et al., 2005; Reynolds et al., 1995; White and Sully, 1987; White et al., 1989; Wu et al., 1997).

Soil water transmission properties depend on soil structure and should be determined directly in the field to minimize soil disturbance due to sampling and also to maintain the functional connection of the sampled soil volume with the surrounding soil. The Beerkan Estimation of Soil Transfer parameters (BEST) methodology (Lassabatere et al., 2006) appears a good method to determine $S$ and $K_{s}$ in the field since BEST is theoretically robust and practically simple. The method, that makes use of the explicit equations proposed by Haverkamp et al. (1994) for modelling the transient and steady-state infiltration from a circular source, can be applied in different circumstances due to the availability of different data analysis algorithms (Bagarello et al., 2014; Lassabatere et al., 2006; Yilmaz et al., 2010). In particular, BEST-steady (Bagarello et al., 2014) does not require a detailed experimental information on infiltration and it is simpler to apply than the other algorithms (Bagarello and David, 2020; Di Prima et al., 2018). The BEST methodology has become very popular among soil scientists (AnguloJaramillo et al., 2019) and the interest for this method should persist in the future also considering that BEST was recently extended to dual-permeability soils (Lassabatere et al., 2019a).

The measured soil water transmission properties are known to vary with the measurement method and the applied experimental procedure of a given method since they depend on many factors such as sample size, infiltration run duration or established flow geometry (Bagarello and David, 2020; Reynolds et al., 2000; Verbist et al., 2013). However, not everything has been clarified yet, without mentioning the issue of modeling and data treatment as an additional source or uncertainty.

With BEST, water infiltration experiments are generally carried out with the Beerkan method, pioneered by Braud et al. (2005) that became a standard and popular method due to its simplicity (Angulo-Jaramillo et al., 2019). A ring with a diameter of several centimeters is inserted a short distance into the soil to avoid lateral loss of the applied water. A fixed, small volume of water is poured into the cylinder at time zero to establish a small ponded head of water on the infiltration surface and the time, $t_{a}$, elapsed during infiltration of this water volume is measured. When the first volume has completely infiltrated and the soil surface is entirely exposed to air, a second equal volume of water is added to the cylinder and the time needed for it to infiltrate is measured (Lassabatere et al., 2006). The procedure is repeated for about 8 to 15 known volumes and, in any case, until flow into the soil nearly stabilizes (Lassabatere et al., 2019b). Finally, the dataset is made up of a set of $N$ discrete points describing an experimental cumulative infiltration curve. However, other criteria could be applied to establish when the subsequent water volume has to be poured on the infiltration surface. For example, Smith (1999) suggested that the infiltration time of a given water volume could be fixed at $t_{o}$, that is the time when the soil exposition to air begins, or at 
$t_{m}$, that is the time when half the soil surface is exposed. This last time was considered by Smith (1999) for designing his rapid estimation method of soil sorptivity. An effect of the infiltration time criterion (ITC) on the experimental infiltration curve, and hence the estimated soil water transmission properties, cannot be excluded. For example, it can be presumed that, with the $t_{a}$ criterion, some air is entrapped in the sampled soil volume before application of a new dose (Di Prima, 2015). Errors in visual estimation of $t_{m}$ could occur, as also mentioned by Smith (1999). With the $t_{\mathrm{o}}$ criterion, the infiltration process is steadily performed under a small, but non-null ponded head of water (Alagna et al., 2018) although the infiltration model proposed by Haverkamp et al. (1994) is strictly valid for a null ponded depth of water on the infiltration surface. The effect of the ITC for a classical Beerkan run on the soil water transmission properties estimated with BEST is unknown. In particular, it is still necessary to verify if the soil hydraulic characterization should be expected to change when a different ITC than the standard one ( $t_{a}$, Lassabatere et al., 2006) is used.

The objective of this investigation was to test the influence of the infiltration time criterion applied for performing a Beerkan run on the infiltration rates and the water transmission properties of a sandy-loam soil.

\section{THEORY}

The BEST-steady algorithm makes use of the intercept, $b_{s}$ $(\mathrm{L})$, and the slope, $i_{s}(\mathrm{~L} / \mathrm{T})$, of the straight line fitted to the data that describe steady-state conditions on the cumulative infiltration, $I(\mathrm{~L})$, vs. time, $t(\mathrm{~T})$, curve (Bagarello et al., 2014). The following relationships are used to calculate soil sorptivity, $S$ $\left(\mathrm{L} / \mathrm{T}^{0.5}\right)$, and saturated soil hydraulic conductivity, $K_{s}(\mathrm{~L} / \mathrm{T})$ :

$$
\begin{aligned}
& S=\sqrt{\frac{i_{s}}{A+\frac{C}{b_{s}}}} \\
& K_{s}=\frac{C i_{s}}{A b_{s}+C}
\end{aligned}
$$

where $A(1 / \mathrm{L})$ and $C$ are constants that, for an antecedent volumetric soil water content, $\theta_{i}\left(\mathrm{~L}^{3} / \mathrm{L}^{3}\right)$, less than 0.25 times the saturated volumetric soil water content, $\theta_{s}\left(\mathrm{~L}^{3} / \mathrm{L}^{3}\right)$ (Haverkamp et al., 1994; Lassabatere et al., 2006), can be set at:

$$
\begin{aligned}
& A=\frac{\gamma}{r \Delta \theta} \\
& C \approx \frac{1}{2(1-\beta)} \ln \left(\frac{1}{\beta}\right)
\end{aligned}
$$

where $\Delta \theta\left(\mathrm{L}^{3} / \mathrm{L}^{3}\right)$ is $\theta_{s}-\theta_{i}, r(\mathrm{~L})$ is the radius of the infiltration surface and $\gamma$ and $\beta$ are coefficients commonly assumed equal to 0.75 and 0.6 , respectively. When the default value for $\beta$ is considered, the constant $C$ is equal to 0.639 .

In practice, BEST-steady can be applied if only total duration, $d_{t}(\mathrm{~T})$, total infiltrated water, $I_{t}(\mathrm{~L})$, and steady-state infiltration rate, $i_{s}(\mathrm{~L} / \mathrm{T})$, are known for an infiltration run since simple geometric considerations indicate that $b_{s}$ can be expressed as (Bagarello and David, 2020):

$$
b_{s}=I_{t}-d_{t} \cdot i_{s}
$$

Eq. (3) makes the use of BEST-steady practically simple since an estimate of $i_{s}$ can be obtained from the measured infiltration rates close to the end of the run (Di Prima et al., 2020). In other words, a failure for any reason in collecting transient infiltration data precludes development of the cumulative infiltration curve but it does not impede application of the algorithm. The possibility to simplify the experiment increases the attractiveness of the methodology but it should not be viewed as an incentive to avoid collection of transient infiltration data since these data are necessary to verify consistency between theory and practice (Di Prima et al., 2018) and also because they help to establish if the run has stabilized or not at a certain time.

The macroscopic capillary length, $\lambda_{c}(\mathrm{~L})$, that expresses the relative importance of capillarity over gravity forces during water movement in unsaturated soil, is given by (White and Sully, 1987);

$$
\lambda_{c}=\frac{b S^{2}}{\Delta \theta \Delta K}
$$

where $b$ is a dimensionless constant frequently set equal to 0.55 and $\Delta K$ is the difference between $K_{s}$ and the initial soil hydraulic conductivity, $K_{i}(\mathrm{~L} / \mathrm{T})$. According to Di Prima et al. (2020), $\lambda_{c}$ can be determined with a Beerkan infiltration experiment by the following relationship:

$$
\lambda_{c}=0.861 \frac{b_{s}}{\Delta \theta}
$$

Combining Eqs. (3) and (5a) yields:

$$
\lambda_{c}=0.861 \frac{I_{t}-d_{t} \cdot i_{s}}{\Delta \theta}
$$

showing that a limited experimental information could be enough to also estimate $\lambda_{c}$.

The characteristic microscopic pore radius, $\lambda_{m}$, of the soil can be obtained as (White and Sully, 1987):

$$
\lambda_{m}=\frac{\sigma}{\rho g \lambda_{c}}
$$

where $\sigma\left(\mathrm{M} / \mathrm{T}^{2}\right)$ is the surface tension of water, $\rho\left(\mathrm{M} / \mathrm{L}^{3}\right)$ is the density of water, and $g\left(\mathrm{~L} / \mathrm{T}^{2}\right)$ is the acceleration due to gravity. Taking the properties of pure water at $20{ }^{\circ} \mathrm{C}$ as appropriate, $\lambda_{m} \approx 7.4 / \lambda_{c}$ which is valid when $\lambda_{m}$ and $\lambda_{c}$ are expressed in $\mathrm{mm}$. The $\lambda_{m}$ value represents an effective equivalent mean radius of the pores that participate in the infiltration process (Iovino et al., 2016; Reynolds et al., 1995). The larger $\lambda_{m}$ the greater the effect of gravity compared to capillarity as the infiltration driving force (Ndiaye et al., 2005).

According to Wu et al. (1997), $\lambda_{c}$ can be used to estimate the depth of the wetting front at the end of a single-ring infiltration run, $d_{w f}(\mathrm{~L})$, taking into account for lateral flow divergence:

$$
d_{w f}=\frac{I_{t}}{f \Delta \theta}
$$

with $f$ given by:

$$
f=\frac{H+\lambda_{c}}{d+\frac{r}{2}}+1
$$


where $H(\mathrm{~L})$ is the steady depth of ponding on the infiltration surface and $d(\mathrm{~L})$ is the depth of ring insertion into the soil.

The soil water transmission parameters considered here quantitatively express the dominant driving force in an infiltration process, the relative importance of soil water conducting porosity and the extent of the wetting front for a threedimensional infiltration process. Together with the soil hydrodynamic parameters, $K_{S}$ and $S$, they allow a complete characterization of the infiltration process from a single ring into an initially unsaturated soil. Apart from the saturated hydraulic conductivity, the soil transmission parameters vary with the initial soil water content. Therefore, it is of practical interest to investigate how the experimental infiltration time criterion applied for performing a Beerkan run could affect their estimation under different initial soil conditions.

\section{MATERIALS AND METHODS Field site}

The field experiment was carried out at the so-called "Aranceto" site, that was established at the Department of Agricultural, Food and Forest Sciences of the Palermo (Italy) University (38 $06^{\prime} 24^{\prime \prime} \mathrm{N}, 13^{\circ} 21^{\prime} 06^{\prime}$ ' E). An approximately $150 \mathrm{~m}^{2}$ flat area of a citrus orchard, with trees spaced $4 \mathrm{~m} \times 4 \mathrm{~m}$ apart, was selected. Disturbed soil samples were collected from the upper $0-0.10,0.10-0.20$ and $0.20-0.30 \mathrm{~m}$ of the profile to determine the soil particle size distribution using conventional methods following $\mathrm{H}_{2} \mathrm{O}_{2}$ pre-treatment to eliminate organic matter and clay deflocculation with sodium hexametaphosphate and mechanical agitation. The soil texture of the upper $0.3 \mathrm{~m}$ of the profile was sandy-loam according to the USDA classification (Table 1). The mean organic carbon content, OC (\%), of the upper few centimeters of the soil, determined by Auteri et al. (2020) with the Walkley-Black method, was equal to 3.1\%.

\section{Experiments}

Field infiltration experiments of the Beerkan type (Braud et al., 2005; Lassabatere et al., 2006) were carried out in summer and autumn 2020. The main features of these experiments were: i) insertion of $0.08-\mathrm{m}$-diam. rings to a depth of $0.01 \mathrm{~m}$ on the soil surface; ii) filling plastic glasses with $57 \mathrm{~mL}$ of water, corresponding to a water infiltration depth of $11.3 \mathrm{~mm}$; iii) successively pouring the water contained in a glass on the confined infiltration surface from a height of nearly $0.03 \mathrm{~m}$. In particular, each fixed volume of water was poured in the ring in approximately $3 \mathrm{~s}$ and the elapsed time during infiltration was measured. Identical amounts of water were subsequently poured into the ring, and the time needed for each water volume to infiltrate was logged. Although the existing guidelines suggest that 15 water volumes should generally be enough to collect nearly steady infiltration data (Lassabatere et al., 2006), 20 water volumes were used at a sampling point in this investigation to possibly improve estimation of the steady-state infiltration rate (Lassabatere et al., 2019b; Souza et al., 2014). A total of eight infiltration datasets were developed by performing, for each dataset, 16 runs at randomly chosen points of the field site.

The first four datasets were collected from June 29 to July 14,2020 by different experimental procedures with reference to the application time of a new water volume after infiltration of the previous one. In particular, the three criteria described by Smith (1999) were applied. Consequently, a dataset was developed by applying the new water volume when the first point of the infiltration surface begins to emerge over the falling water ( $t_{o}$ dataset). Another dataset was collected by pouring a new water volume when half the soil surface was visually exposed to air $\left(t_{m}\right.$ dataset). For the third dataset, the standard protocol suggested by Lassabatere et al. (2006) for applying BEST methods was applied. In particular, the time when the last free water disappeared was considered ( $t_{a}$ dataset). A fourth dataset was developed by applying the new water volume three minutes after complete infiltration of the previously applied water volume, attempting to induce some short-term soil water redistribution between two subsequent water applications ( $t_{a 3}$ dataset). The other four datasets were collected from November 3 to 16 with exactly the same experimental procedures $\left(t_{o}, t_{m}, t_{a}\right.$, $\left.t_{a 3}\right)$. Comparison between data collected in July and November was established to explore the dependency of the soil water transmission properties estimated by different ITC on the initial soil water content.

Soil was repeatedly sampled during the two experimental periods to determine the dry soil bulk density, $\rho_{b}\left(\mathrm{~g} / \mathrm{cm}^{3}\right)$, and the volumetric soil water content, $\theta\left(\mathrm{cm}^{3} / \mathrm{cm}^{3}\right)$. On a given day, undisturbed soil cores $(0.05 \mathrm{~m}$ in height by $0.05 \mathrm{~m}$ in diameter) were collected at the 0 to $0.05 \mathrm{~m}$ and 0.05 to $0.10 \mathrm{~m}$ depths at three randomly chosen sampling points. These six cores were used to determine $\rho_{b}$ and the gravimetric soil water content, $w$ $(\mathrm{g} / \mathrm{g})$, and hence $\theta$, in the laboratory. The data were averaged to obtain, for a given day, a $\rho_{b}$ and a $\theta$ value of the upper $0.10 \mathrm{~m}$ of the soil. The saturated soil water content, $\theta_{s}\left(\mathrm{~cm}^{3} / \mathrm{cm}^{3}\right)$, necessary to apply BEST, was estimated from $\rho_{b}$ assuming that $\theta_{s}$ coincided with porosity (Mubarak et al., 2009).

\section{Calculations and data analysis}

The infiltration rate of each applied water volume, $i_{r}(\mathrm{~mm} / \mathrm{h})$, was obtained by the ratio between the depth of the infiltrated water $(11.3 \mathrm{~mm})$ and the associated infiltration time. The mean infiltration rate for a run, $i_{\text {med }}(\mathrm{mm} / \mathrm{h})$, was calculated as the ratio between total cumulative infiltration $(226.8 \mathrm{~mm})$ and total infiltration time. For the $t_{a 3}$ dataset, the total duration considered for the $i_{\text {med }}$ calculations was the duration of the infiltration process net of all the 3-min breaks between complete infiltration of a water volume and application of the subsequent one.

The intercept, $b_{s}(\mathrm{~mm})$, and the slope, $i_{s}(\mathrm{~mm} / \mathrm{h})$, of the straight line fitted by linear regression to the data describing steady-state conditions on the cumulative infiltration, $I(\mathrm{~mm})$, vs. time, $t(\mathrm{~h})$, curve were determined for each $t_{o}, t_{m}$ and $t_{a}$ run by considering in most cases the last three $(I, t)$ data pairs.

Table 1. Soil textural characteristics at the field site (Sample size $N=6$ ).

\begin{tabular}{|c|c|c|c|c|c|c|}
\hline \multirow{2}{*}{ Depth (m) } & \multicolumn{2}{|c|}{ Clay (\%) } & \multicolumn{2}{c|}{ Silt (\%) } & \multicolumn{2}{c|}{ Sand (\%) } \\
\cline { 2 - 7 } & Mean & CV (\%) & Mean & CV (\%) & Mean & CV (\%) \\
\hline $0-0.10$ & 15.5 & 13.0 & 29.6 & 4.2 & 54.9 & 4.9 \\
\hline $0.10-0.20$ & 14.4 & 8.3 & 30.2 & 5.4 & 55.4 & 4.1 \\
\hline $0.20-0.30$ & 15.0 & 13.2 & 29.6 & 4.9 & 55.4 & 4.9 \\
\hline
\end{tabular}

$\mathrm{CV}=$ coefficient of variation 
The BEST-steady algorithm (Bagarello et al., 2014) was then used to calculate the soil sorptivity, $S\left(\mathrm{~mm} / \mathrm{h}^{0.5}\right)$, and the saturated soil hydraulic conductivity, $K_{s}(\mathrm{~mm} / \mathrm{h})$, with Eq. (1). This choice was made since BEST-steady should be more robust than the other existing algorithms, that is BEST-slope (Lassabatere et al., 2006) and BEST-intercept (Yilmaz et al., 2010), at least in certain circumstances (Angulo-Jaramillo et al., 2019; Di Prima et al., 2018). For each infiltration run, the macroscopic capillary length, $\lambda_{c}(\mathrm{~mm})$, the effective equivalent mean pore radius, $\lambda_{m}(\mathrm{~mm})$ and the depth of the wetting front at the end of the run, $d_{w f}(\mathrm{~mm})$, were then calculated by Eqs. (5a), (6), (7) and (8), respectively. The depth of ponding in Eq. (8) was set equal to zero. For comparison purposes, another estimate of $\lambda_{c}$ was obtained by Eq. (5b). Infiltration was not continuous with the $t_{a 3}$ methodology because there was a pause between two subsequent water applications. Consequently, soil water transmission properties were not calculated for these runs.

The Lilliefors (1967) test was applied at $P=0.05$ to test the normal distribution hypothesis of both the untransformed $(\mathrm{N})$ and the ln-transformed (LN) infiltration data and derivatives for each of the eight datasets. In particular, this check was made with reference to $i_{m e d}, b_{s}, i_{s}, S, K_{s}, \lambda_{c}, \lambda_{m}$ and $d_{w f}$. The arithmetic mean and the associated coefficient of variation, $\mathrm{CV}$, were used to summarize the data when they were assumed normally distributed. The geometric mean and the associated $\mathrm{CV}$ were calculated (Lee et al., 1985) when the data were assumed lnnormally distributed.

Several pairwise comparisons were established between two datasets by performing $\mathrm{F}$ and two-tailed t tests at $P=0.05$ on the untransformed or the ln-transformed data, depending on the distribution of considered variable. A pairwise comparison was preferred to other alternative statistical tests since establishing differences between, e.g., the $t_{o}$ and $t_{m}$ data does not depend on the information collected with the $t_{a}$ or $t_{a 3}$ infiltration time criteria. Unpaired t tests were performed since each individual run was carried out at a different location of the field site. In particular, comparisons between the $i_{m e d}, b_{s}, i_{s}, S, K_{s}, \lambda_{c}, \lambda_{m}$ and $d_{w f}$ datasets obtained with different infiltration time criteria were performed for both the summer and the autumn sampling campaigns. A comparison was also established between the results obtained in the two campaigns with each ITC.

\section{RESULTS}

The soil was significantly denser and drier in summer than in autumn but, even in the condition of maximum wetness, $\theta_{i} / \theta_{s}$ did not exceed 0.24 (Table 2). Therefore, the ITC effects were tested under two different antecedent conditions in terms of both $\rho_{b}$ and $\theta_{i}$. The BEST equations were properly applied since the $\theta_{i} / \theta_{s}$ value discriminating between possible and nonrecommended application of the BEST methodology $\left(\theta_{i} / \theta_{s}=\right.$
0.25; Lassabatere et al., 2006) was not exceeded in any day of the two sampling periods.

The infiltration rate curves, plotted against cumulative infiltration to facilitate comparisons between ITC, revealed a superposition of the data collected with different criteria (Fig. 1). However, in both sampling dates, $i_{r}$ was overall highest with the $t_{o}$ and $t_{m}$ criteria, intermediate with the $t_{a}$ criterion and lowest with the $t_{a 3}$ criterion. Therefore, soil spatial variability did not impede detection of an ITC effect on infiltration rates. In the passage from the drier to the wetter season, the bundle of curves moved towards a lower zone of the $\left(i_{r}, I\right)$ plane although a wide range of $i_{r}$ values was common to the two sampling dates.

To compare infiltration time criteria for a sampling date and dates for a given ITC, a unique distribution (i.e., normal or lnnormal) was considered for each of the eight $i_{\text {med }}$ datasets or the six $b_{s}, i_{s}, S, K_{s}, \lambda_{c}, \lambda_{m}$ and $d_{w f}$ datasets. In other words, for a given variable, all the available datasets were assumed to have the same statistical distribution. In particular, the assumed distribution of a particular variable was the distribution that was not rejected for all datasets and/or gave the best results in the majority of the cases. Consequently, $i_{m e d}, b_{s}, i_{s}, S$ and $\lambda_{c}$ were assumed normally distributed. Instead, $K_{s}, \lambda_{m}$ and $d_{w f}$ were assumed ln-normally distributed.

The main features of each infiltration process were summarized by $b_{s}$, since it is related to the concavity of the cumulative infiltration curve (Angulo-Jaramillo et al., 2019), $i_{\text {med }}$, since it is easier to compare quantitative indicator of infiltration than curves (Lassabatere et al., 2019b), and $i_{s}$, since the steady-state infiltration rate is used by any BEST algorithm of data analysis (Fig. 2). Neither the ITC nor the sampling date had any statistically detectable effect on $b_{s}$ (Table 3 ). Therefore, the intercept of the straight line fitted to the data describing steady-state conditions was insensitive to both the applied method to perform the Beerkan experiment and the time of the year when the experiment was carried out. Instead, some effects of the experimental method and the time of the year were detected with reference to $i_{\text {med }}$ and $i_{s}$, for which statistical results were similar. In particular, the standard ITC $\left(t_{a}\right)$ suggested significant differences between the two sampling dates since the summer infiltration rates $\left(i_{m e d}, i_{s}\right)$ were approximately 1.7 times greater than those measured in autumn. The $t_{o}$ criterion yielded higher infiltration rates than the $t_{a}$ one by 1.3-1.5 times, depending on the considered variable $\left(i_{m e d}, i_{s}\right)$ and the sampling campaign (summer, autumn). However, differences between the two campaigns remained perceivable even with the $t_{o}$ criterion although they were a little smaller since, in this case, the summer $i_{\text {med }}$ and $i_{s}$ values were approximately 1.5 times greater than the autumn values. The $t_{m}$ criterion yielded higher infiltration rates than the $t_{a}$ criterion for both sampling campaigns (1.4-1.5 times in autumn and 1.1 times in summer) but only in the first case the differences were statistically significant. Between the two

Table 2. Summary statistics of the dry soil bulk density, $\rho_{b}$, antecedent volumetric soil water content, $\theta_{i}$, and ratio between $\theta_{i}$ and the saturated volumetric soil water content, $\theta_{\mathrm{s}}$, for the two sampling campaigns.

\begin{tabular}{|c|c|c|c|c|c|c|}
\hline \multirow[t]{2}{*}{ Statistic } & \multicolumn{2}{|c|}{$\rho_{b}\left(\mathrm{~g} / \mathrm{cm}^{3}\right)$} & \multicolumn{2}{|c|}{$\theta_{i}\left(\mathrm{~cm}^{3} / \mathrm{cm}^{3}\right)$} & \multicolumn{2}{|c|}{$\theta_{i} / \theta_{s}$} \\
\hline & Summer & Autumn & Summer & Autumn & Summer & Autumn \\
\hline$N$ & 10 & 9 & 10 & 9 & 10 & 9 \\
\hline Min & 1.099 & 1.034 & 0.049 & 0.116 & 0.09 & 0.20 \\
\hline Max & 1.203 & 1.099 & 0.114 & 0.146 & 0.21 & 0.24 \\
\hline Mean & $1.156(\mathrm{a})$ & 1.059 (a) & $0.068(\mathrm{~b})$ & 0.138 (b) & $0.12(\mathrm{c})$ & $0.23(\mathrm{c})$ \\
\hline CV (\%) & 2.7 & 1.9 & 26.5 & 6.6 & 27.0 & 5.8 \\
\hline
\end{tabular}

$N=$ sample size; $\mathrm{Min}=$ minimum value; $\mathrm{Max}=$ Maximum value; $\mathrm{CV}=$ coefficient of variation. Means followed by the same lower case letter enclosed in parenthesis are significantly different according to a two-tailed $t$ test at $P=0.05$. 

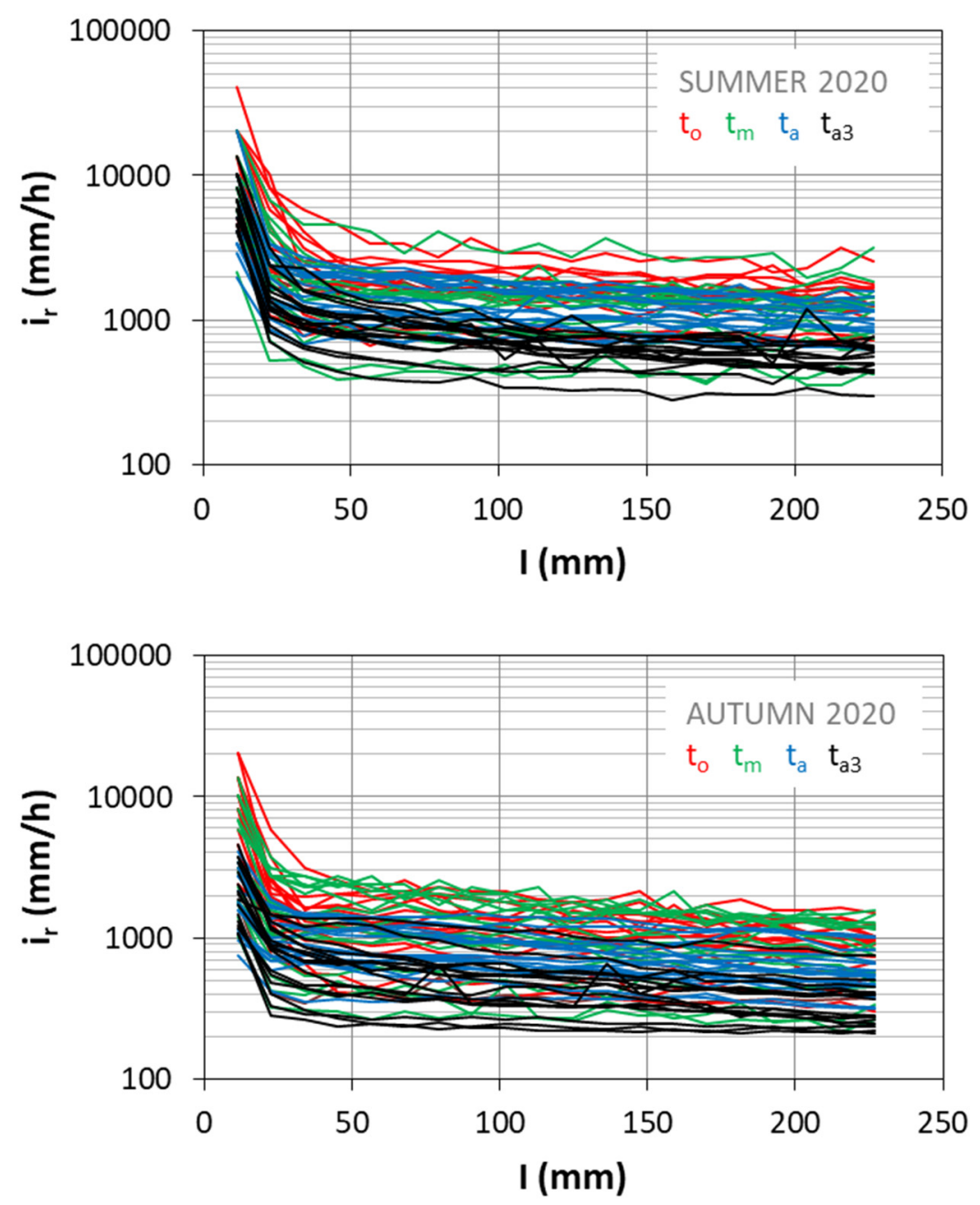

Fig. 1. Infiltration rates, $i_{r}$, measured with different infiltration time criteria against cumulative infiltration, $I$, for the two sampling campaigns $\left(t_{o}=\right.$ the first point of the infiltration surface begins to emerge, $t_{m}=$ half the soil surface is exposed to air, $t_{a}=$ the entire surface is exposed to air, $t_{a 3}=$ three minutes after the complete infiltration of water).

Table 3. Summary statistics of mean infiltration rate $\left(i_{m e d}\right)$, intercept $\left(b_{s}\right)$ and slope $\left(i_{s}\right)$ of the straight line fitted to the data describing steady-state conditions on the cumulative infiltration curve, sorptivity $(S)$, saturated soil hydraulic conductivity $\left(K_{s}\right)$, macroscopic capillary length $\left(\lambda_{c}\right)$, representative mean pore radius $\left(\lambda_{m}\right)$ and depth of the wetting front at the end of the run $\left(d_{w f}\right)$ obtained with the $t_{o}, t_{m}, t_{a}$ and $t_{a 3}$ infiltration time criteria on two sampling dates.

\begin{tabular}{|c|c|c|c|c|c|c|c|c|c|}
\hline \multirow[t]{2}{*}{ Variable } & \multirow[t]{2}{*}{ Statistic } & \multicolumn{4}{|c|}{ July 2020} & \multicolumn{4}{|c|}{ November 2020} \\
\hline & & $t_{o}$ & $t_{m}$ & $t_{a}$ & $t_{a 3}$ & $t_{o}$ & $t_{m}$ & $t_{a}$ & $t_{a 3}$ \\
\hline \multirow{2}{*}{$\begin{array}{c}i_{\text {med }} \\
(\mathrm{mm} / \mathrm{h})\end{array}$} & Mean & 1707.7 ac $\mathbf{A}$ & $1420.1 \mathrm{ab} \mathrm{B}$ & 1305.4 bed C & 708.4 d D & 1157.2 ac $\mathbf{A}$ & 1138.0 ab B & 771.1 bed C & 482.2 d D \\
\hline & CV (\%) & 35.7 & 47.2 & 29.0 & 23.1 & 41.4 & 48.2 & 34.1 & 43.4 \\
\hline \multirow{2}{*}{$\begin{array}{c}b_{s} \\
(\mathrm{~mm})\end{array}$} & Mean & $41.5 \mathrm{ac} \mathrm{A}$ & $39.5 \mathrm{ab} \mathrm{B}$ & $48.0 \mathrm{bc} \mathrm{C}$ & - & $44.0 \mathrm{ac} \mathrm{A}$ & $50.8 \mathrm{ab} \mathrm{B}$ & $51.2 \mathrm{bc} \mathrm{C}$ & - \\
\hline & CV (\%) & 34.7 & 30.6 & 35.3 & - & 41.4 & 45.5 & 32.7 & - \\
\hline \multirow{2}{*}{$\begin{array}{c}i_{s} \\
(\mathrm{~mm} / \mathrm{h})\end{array}$} & Mean & 1381.9 ac $\mathbf{A}$ & $1151.9 \mathrm{ab} \mathrm{B}$ & 1015.2 bc C & - & 914.2 ac $\mathbf{A}$ & $855.5 \mathrm{ab}$ B & 595.6 bc C & - \\
\hline & CV (\%) & 33.7 & 43.0 & 26.0 & - & 38.7 & 44.7 & 35.8 & - \\
\hline \multirow{2}{*}{$\begin{array}{c}S \\
\left(\mathrm{~mm} / \mathrm{h}^{0.5}\right) \\
\end{array}$} & Mean & 155.6 ac $\mathbf{A}$ & $141.5 \mathrm{ab} B$ & $137.4 \mathrm{bc} \mathrm{C}$ & - & 124.6 ac A & $120.8 \mathrm{ab} \mathrm{B}$ & 103.2 bc C & - \\
\hline & CV (\%) & 19.5 & 24.6 & 14.9 & - & 23.9 & 29.5 & 17.2 & - \\
\hline \multirow{2}{*}{$\begin{array}{c}K_{s} \\
(\mathrm{~mm} / \mathrm{h}) \\
\end{array}$} & Mean & 388.5 ac A & $318.2 \mathrm{ab} \mathbf{B}$ & 263.5 bc C & - & 230.9 ac $\mathbf{A}$ & $192.3 \mathrm{ab} \mathbf{B}$ & 136.8 bc C & - \\
\hline & CV (\%) & 45.3 & 46.0 & 33.7 & - & 48.0 & 59.2 & 49.8 & - \\
\hline \multirow{2}{*}{$\begin{array}{c}\lambda_{c} \\
(\mathrm{~mm})\end{array}$} & Mean & 72.9 ac A & $69.1 \mathrm{ab} \mathbf{B}$ & 84.3 bc C & - & 81.6 ac $\mathrm{A}$ & $94.5 \mathrm{ab} \mathbf{B}$ & 95.3 bc C & - \\
\hline & CV (\%) & 36.2 & 30.9 & 36.8 & - & 40.8 & 45.5 & 32.7 & - \\
\hline \multirow{2}{*}{$\begin{array}{c}\lambda_{m} \\
(\mathrm{~mm})\end{array}$} & Mean & $0.111 \mathrm{ac} \mathrm{A}$ & $0.112 \mathrm{ab} \mathrm{B}$ & $0.095 \mathrm{bc} \mathrm{C}$ & - & $0.099 \mathrm{ac} \mathrm{A}$ & $0.091 \mathrm{ab} \mathrm{B}$ & $0.082 \mathrm{bc} \mathrm{C}$ & - \\
\hline & CV (\%) & 50.2 & 32.1 & 44.2 & - & 46.0 & 69.9 & 38.6 & - \\
\hline \multirow{2}{*}{$\begin{array}{c}d_{w f} \\
(\mathrm{~mm})\end{array}$} & Mean & 138.9 ac A & $142.2 \mathrm{ab} \mathrm{B}$ & $125.3 \mathrm{bc} \mathrm{C}$ & - & $137.4 \mathrm{ac} \mathrm{A}$ & $126.6 \mathrm{ab} \mathrm{B}$ & $121.2 \mathrm{bc} \mathrm{C}$ & - \\
\hline & CV (\%) & 27.8 & 21.1 & 28.0 & - & 31.6 & 42.6 & 27.3 & - \\
\hline
\end{tabular}

$\mathrm{CV}=$ coefficient of variation. For each sampling date, means of a given variable followed by the same lower case letter in bold are significantly different according to a two-tailed t test at $P=0.05$. For each infiltration time criterion, means of a given variable collected at the two sampling dates followed by the same upper case letter in bold are significantly different according to a two-tailed test at $P=0.05$. 

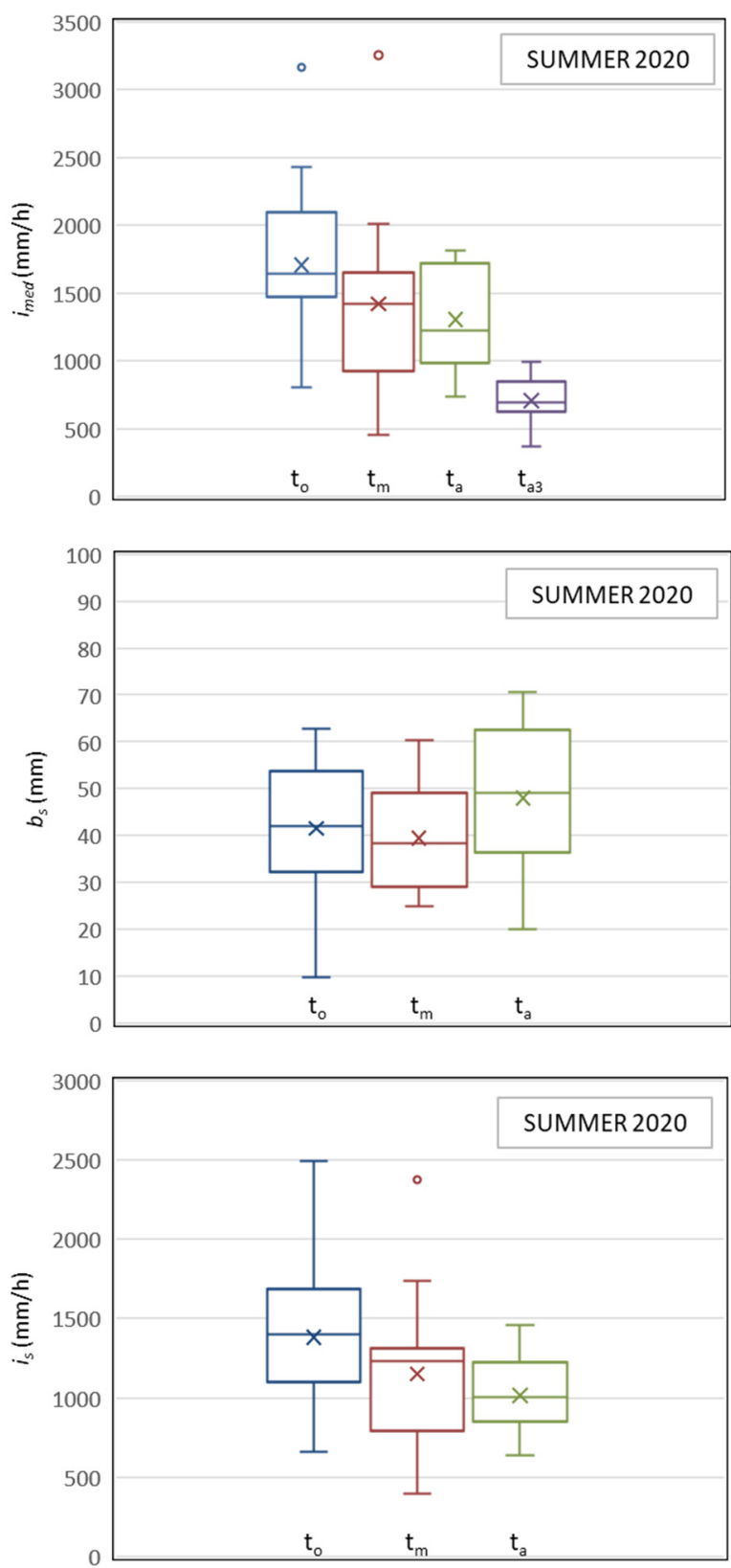
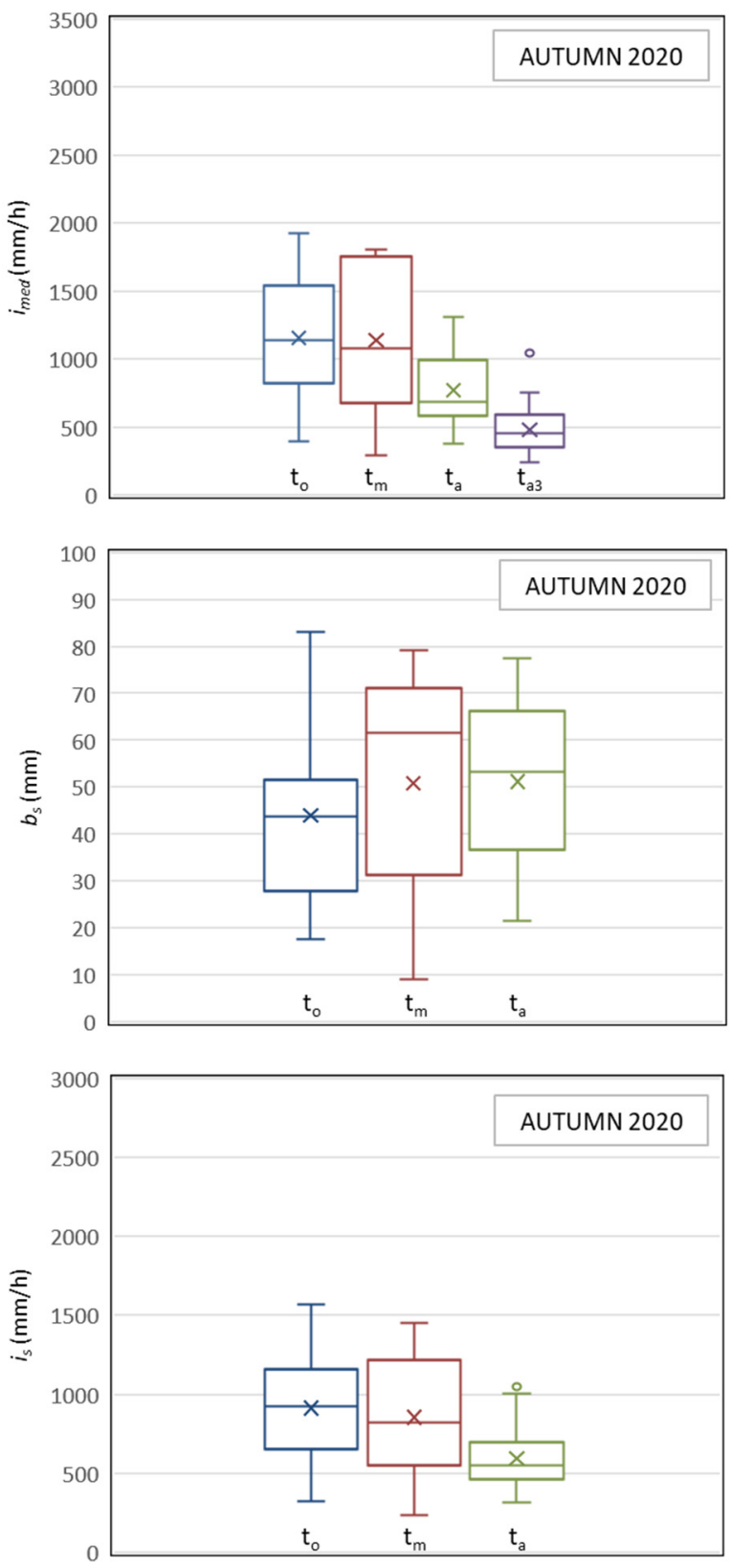

Fig. 2. Box plots of mean infiltration rate, $i_{m e d}(\mathrm{~mm} / \mathrm{h})$, intercept, $b_{s}(\mathrm{~mm})$, and the slope, $i_{s}(\mathrm{~mm} / \mathrm{h})$, of the regression line describing steadystate conditions for the two sampling campaigns (boundaries of the box indicate median, 25 th and $75^{\text {th }}$ quantiles, crossed points indicate mean, top and bottom whiskers indicate the minimum and maximum values, circles indicate outliers).

sampling campaigns, no statistically significant differences were noticed for $i_{m e d}$ and $i_{s}$.

Therefore, the $t_{o}$ criterion determined a significant increase of the infiltration rates as compared with the standard $t_{a}$ criterion but it did not impede detecting differences between two sampling campaigns. With the $t_{m}$ criterion, infiltration rates were more similar to those obtained with the standard criterion. However, using the $t_{m}$ criterion made differences between campaigns undetectable. Probably, this last result occurred since the $t_{m}$ criterion was more subjective than the other two tested criteria and consequently it yielded the most variable $i_{m e d}$ and $i_{s}$ values.

The $i_{\text {med }}$ values obtained with the $t_{a 3}$ criterion were smaller than those obtained with the standard criterion by 1.8 times in summer and 1.6 times in autumn (Table 3). Moreover, introducing a pause between two successive water applications implied that $i_{\text {med }}$ decreased by 1.5 times from summer to autumn, which is a slightly smaller decrease as compared with that corresponding to the standard Beerkan experiment.

The effect of the ITC varied with the considered water transmission property $\left(S, K_{s}, \lambda_{c}, \lambda_{m}\right)$. According to the standard criterion, $S$ and $K_{s}$ decreased by 1.3 and 1.9 times, respectively, in the passage from summer to autumn whereas the other properties did not change significantly (Table 3 ). Differences between the $t_{o}$ and $t_{a}$ criteria were detected for $K_{s}$ on both sampling dates, since the former criterion yielded higher $K_{s}$ values than the latter one by 1.5-1.7 times, and for $S$ only in autumn, when the $t_{o}$ calculations were 1.2 times higher than the $t_{a}$ results. Differences between the $t_{o}$ and $t_{a}$ criteria were not significant for $\lambda_{c}$ and $\lambda_{m}$. Even the $t_{o}$ criterion suggested that $S$ and $K_{s}$ decreased between the two sampling campaigns, 
although by a slightly smaller amount (1.2 times for $S$ and 1.7 times for $K_{s}$ ) as compared with the $t_{a}$ criterion, while the other water transmission properties did not change. There was not any significant difference between the $t_{m}$ and $t_{a}$ criteria for each variable and for both sampling dates. With the $t_{m}$ criterion, $K_{s}$ decreased by 1.7 times from summer to autumn but $S$ remained stable. The same result was obtained for $\lambda_{m}$ whereas $\lambda_{c}$ increased by 1.4 times.

Therefore, the $t_{o}$ criterion determined a significant increase of $K_{s}$ as compared with the $t_{a}$ criterion but this circumstance did not impede detecting differences between the two sampling campaigns. An increase of $S$ only occurred at the second sampling campaign and the time effects remained detectable. The $t_{m}$ and $t_{a}$ criteria yielded statistically similar $S$ and $K_{s}$ values. Temporal variability of $K_{s}$ remained detectable even with the $t_{m}$ criterion while that of $S$ disappeared. Moreover, the $t_{m}$ criterion induced appearance of a time effect for $\lambda_{c}$ that was not perceived with the $t_{a}$ criterion. Probably, $\lambda_{c}$ and $\lambda_{m}$ were generally unaffected by both the applied criterion and the sampling date as they were estimated by Eqs. (4) and (6), i.e. using $b_{s}$ that was statistically stable.

In an ideal condition, $K_{s}$, which depends on pore geometry, should not vary whereas $S$ is expected to decrease when the initial soil water content increases as the capillary contribution to flow is reduced in relatively wet conditions (AnguloJaramillo et al., 2016). According to this investigation, $S$ decreased as expected from July to November but not so much to induce appearance of statistically significant differences between the two dates. Therefore, $S$, as well as $\lambda_{c}$ and $\lambda_{m}$, could not vary significantly when the antecedent soil water content remains in the range of values that assure proper application of the BEST methodology (Lassabatere et al., 2006). The decrease of $K_{s}$ in wetter soil was consistent with previous investigations that were performed at the same field site. In particular, an inverse relationship between $K_{s}$ and $\theta_{i}$ was also detected by Bagarello and Sgroi (2007) and Alagna et al. (2016) and it was attributed to moderate swelling phenomena and weakening of the interparticle bonds reducing macropore volume in wet soil.

On both sampling dates, the average $\lambda_{c}$ values fell within the moderate capillarity category $\left(42 \leq \lambda_{c} \leq 125 \mathrm{~mm}\right)$, as defined by Di Prima et al. (2020), and changing the ITC did not modify the soil capillarity category assessment. Moreover, using Eq. (5b) as an alternative to Eq. (5a) did not modify the calculation of $\lambda_{c}$ since the percentage differences between the two estimates varied from $-1.4 \%$ to $4.9 \%$.

The $\lambda_{m}$ values obtained in this investigation $(0.082-0.112$ $\mathrm{mm}$, depending on the ITC and the sampling date, Table 3) fell in the range of the $\lambda_{m}$ values $(0.062-0.138 \mathrm{~mm})$ obtained with the same experimental method (Beerkan infiltration) in a soil having a clay content (17\%) similar to that of the "Aranceto" soil (Table 1) (Mubarak et al., 2009). Instead, moderately higher $\lambda_{m}$ values $(0.14-0.17 \mathrm{~mm})$ were obtained in a soil slightly richer in clay (23\%; Souza et al., 2014). According to these data, the $\lambda_{m}$ values obtained with a Beerkan infiltration experiment could be expected to increase with the clay content, perhaps as a consequence of a better aggregation of the soil particles. However, this suggestion would require additional testing since the available experimental information is currently too limited.

Even $d_{w f}$, which is a quantitative indicator of water infiltration (Lassabatere et al., 2019b), did not change with the applied infiltration time criterion and the sampling campaign which was plausible taking into account that Eq. (8) was applied with the estimated $\lambda_{c}$ value by Eq. (4). At the end of the run, the wetting front reached a depth of nearly $12-14 \mathrm{~cm}$. Therefore, sampling the soil to a depth of $10 \mathrm{~cm}$ for determining $\rho_{b}$ and $\theta_{i}$ was acceptable, although in the future it could be advisable to go a little more in depth. Instead, the sampling of the soil textural characteristics was fully appropriate to describe the wetted soil layer by the infiltration run.

In summary, the applied ITC was an experimental factor influencing soil hydraulic characterization, especially with reference to $K_{s}$ that was the most sensitive water transmission property to the applied experimental methodology.

\section{DISCUSSION}

The experimental information collected in this investigation was thought to be rather complete since it ranged from a nearly continuous wetting process ( $t_{o}$ criterion) to a process that very likely included some short-term soil water redistribution between two successive water applications ( $t_{a 3}$ criterion).

The statistical significance of the differences between different infiltration time criteria (Table 3) appeared plausible from a physical point of view. In particular, the following four factors likely contributed to determine more rapid $t_{o}$ than $t_{a}$ runs:

i) with the former criterion, the new water volume was applied when there was still water on the infiltration surface that, instead, was totally exposed to air with the latter criterion. Therefore, the $t_{o}$ run was carried out with a higher mean ponding depth of water than the $t_{a}$ run although by only a few millimeters. Depth of ponding should be null to apply BEST methods of data analysis (Haverkamp et al., 1994; Lassabatere et al., 2006) but, in practice, small and null ponded depths of water are often assumed to denote the same physical quantity. This assumption was supported by Touma et al. (2007) since they suggested that the infiltration process should not depend appreciably on the ponding depth of water when these depths are small. However, theory establishes that the single-ring infiltration rate into unsaturated soil increases with the ponded depth of water (Dušek et al., 2009; Reynolds and Elrick, 1990). Therefore, the ponding depth effect could be small and perhaps negligible in some instances but it should not be excluded a priori;

ii) single-ring infiltration into unsaturated soil determines development of a saturated soil bulb surrounded by an unsaturated wetting zone (Elrick and Reynolds, 1992a). With the $t_{o}$ criterion, a new water volume is poured when wetting is still occurring. With the $t_{a}$ criterion, there is an additional phase between exposure to air of the first point of the infiltration surface and disappearance of all water. Wetting and water redistribution processes likely occurring simultaneously during this phase can make the wetted soil zone larger. Consequently, soil water pressure head gradients may be smaller when a new water volume is poured on the infiltration surface by the $t_{a}$ criterion than the $t_{o}$ one and this circumstance could explain smaller infiltration rates in the former case;

iii) air entrapment in the initially unsaturated soil during ponded infiltration is a common phenomenon that can reduce, even appreciably, infiltration rates (Cislerova et al., 1988; Dohnal et al., 2016). If air entrapment initially occurred, it was likely similar for the $t_{o}$ and $t_{a}$ runs since the experimental methodology was the same at the beginning of these experiments. However, water redistribution during the run only occurred with the $t_{a}$ criterion. This process likely promoted some emptying of the largest pores meaning that the soil was slightly unsaturated in this case when the new water volume was poured on the soil surface. Therefore, there were repeated opportunities to entrap air in the soil during the run and this circumstance likely determined smaller infiltration rates with the $t_{a}$ criterion; 
iv) mechanical disturbance of the soil surface was more appreciable for the $t_{a}$ runs than the $t_{o}$ runs. The reason was that a new water volume was applied directly on an exposed soil surface in the former case and on a soil surface covered by a thin water layer, maybe protecting the soil to some degree, in the latter case.

The $t_{a 3}$ experiment corroborated the soil water pressure head gradient and air entrapment explanations. There was more time for water redistribution with the $t_{a 3}$ criterion than the $t_{a}$ one and this was the only difference between the two experiments. Therefore, at the beginning of a new water volume application, the wetted soil zone was larger and more unsaturated with the $t_{a 3}$ criterion than the $t_{a}$ one. This circumstance implied smaller soil water pressure head gradients, more voids to be filled with water and hence more opportunities to entrap air with a new water volume application. Consequently, infiltration rates were smaller when a pause of three minutes was introduced between complete infiltration of a given amount of water and application of a new volume. Ponding depth and mechanical disturbance did not have any impact on the measured differences between the $t_{a}$ and $t_{a 3}$ experiments since the same water volume was poured on a totally exposed soil surface in both cases.

This investigation suggested that the applied ITC can influence soil hydraulic characterization. The circumstance that the most appreciable differences between alternative criteria were detected for $K_{s}$ (Table 3) reinforced the suggestion that $K_{s}$ should generally be viewed as a kind of sentinel soil property (Auteri et al., 2020; Reynolds et al., 2000). However, $K_{s}$ estimates differed at the most by 1.7 times with the applied ITC, which could not represent a substantial difference. In particular, Elrick and Reynolds (1992b) suggested that $K_{s}$ values differing by two or three times could be considered rather similar, at least for some practical purposes. In other terms, effects of the ITC on soil hydraulic characterization were statistically perceivable but not substantial.

It is plausible to have some perplexity about the infiltration time criterion that should be used to perform a Beerkan run since there is a discrepancy between theory and practice in any case. Theoretically, a continuous infiltration process should be established under a null pressure head on the infiltration surface to be fully consistent with the used infiltration model in BEST (Haverkamp et al., 1994; Lassabatere et al., 2006). However, none of the tested criteria in this investigation $\left(t_{o}, t_{m}, t_{a}\right)$ was strictly consistent with theory because the initial depth of water was $>0$ and a falling-head infiltration process was established in all cases. Moreover, some exposure of the soil surface to air occurred intermittently with the latter two criteria. This investigation also yielded some practical suggestion on the ITC that should be adopted in practice. In particular, variability of infiltration parameters and derived water transmission properties was highest with the $t_{m}$ criterion in 13 cases out of 18 (9 parameters $\times 2$ sampling dates) and lowest with the $t_{a}$ criterion in 12 cases (Table 3 ). Less variability implies more confidence in the reliability of the mean value as a spatially representative parameter for the sampled field site (Picciafuoco et al., 2019). Therefore, the $t_{a}$ criterion by Lassabatere et al. (2006) generally yielded the most representative mean values of infiltration parameters and water transmission properties at the experimental site. Consequently, the general recommendation is to use the $t_{a}$ criterion. More variable ( $t_{o}$ and $t_{m}$ criteria), and hence less representative, and also higher ( $t_{o}$ criterion) estimates can be expected, particularly for $K_{s}$, if alternative criteria are used. However, a different choice could be suggested in case of dualpermeability soils in which macropores extending to the soil surface may be intermittently activated and deactivated by the $t_{a}$ criterion (Lassabatere et al., 2014). In this case, application of $t_{o}$ criterion could be preferable. At this aim, an opportunity is offered by the automated infiltrometer that allows to regulate the height of ponded water so that the surface confined by the ring is entirely submerged under a practically negligible, i.e., 2-3 mm, water depth (Concialdi et al., 2020; Di Prima, 2015; Di Prima et al., 2016).

\section{CONCLUSIONS}

The standard method to perform the classical Beerkan run establishes that a new volume of water has to be poured on the infiltration surface when the previous volume has completely infiltrated. However, water could alternatively be applied when the first soil is exposed by falling water or half the soil surface is exposed.

In this investigation, the effect of the infiltration time criterion (ITC) to perform a Beerkan run on the water transmission properties estimated with the BEST method of soil hydraulic characterization was tested for a sandy-loam soil.

The main finding was that alternative infiltration time criteria can yield statistically different results, although differences could be considered small or also negligible at least for certain practical purposes. In particular, applying the new volume of water before complete disappearance of the previous water volume can yield higher and/or more variable estimates of the water transmission properties and particularly of the saturated soil hydraulic conductivity, for which the role of sentinel soil property was confirmed. Likely, an effect of ITC was noticed because, as compared with the standard Beerkan run methodology, the alternative methods imply an infiltration process governed by greater ponding depths of water, higher soil water pressure head gradients and less relevant air entrapment and mechanical disturbance phenomena at each water volume application.

In practice, the standard method should be applied in the field to perform a Beerkan run since this method can be expected to yield the most representative mean values of infiltration parameters and water transmission properties for the sampled site.

The circumstance that similar results were obtained in two different antecedent soil conditions suggests that the effect of the ITC could be rather common, i.e. also detectable in other soils and antecedent soil water conditions. However, this last suggestion requires support.

According to this investigation, factors that could appear minor or even marginal in the context of an experimental procedure can have a statistically relevant effect on determination of water transmission parameters. Consequently, the practice to develop large datasets by putting soil hydrodynamic data obtained with different methodologies together cannot be recommended. If this is a forced or an advisable choice on the basis of other arguments, caution has to be recommended in interpreting these data given that even a presumably minor factor of an applied experimental methodology (ITC) can have a statistically relevant impact on the collected soil data.

\section{REFERENCES}

Alagna, V., Bagarello, V., Cecere, N., Concialdi, P., Iovino, M., 2018. A test of water pouring height and run intermittence effects on single-ring infiltration rates. Hydrol. Process., 32, 3793-3804. DOI: 10.1002/hyp.13290

Alagna, V., Bagarello, V., Di Prima, S., Giordano, G., Iovino, M., 2016. Testing infiltration run effects on the estimated water transmission properties of a sandy-loam soil. Ge- 
oderma, 267, 24-33. DOI: 10.1016/j.geoderma.2015.12.029

Angulo-Jaramillo, R., Bagarello, V., Di Prima, S., Gosset, A., Iovino, M., Lassabatere, L., 2019. Beerkan Estimation of Soil Transfer parameters (BEST) across soils and scales. Invited Review Paper. J. Hydrol., 576, 239-261. DOI: 10.1016/j.jhydrol.2019.06.007

Angulo-Jaramillo, R., Bagarello, V., Iovino, M., Lassabatere, L., 2016. Infiltration Measurements for Soil Hydraulic Characterization. Springer International Publishing, Cham, 383 p.

Auteri, N., Bagarello, V., Concialdi, P., Iovino, M., 2020. Testing an adapted beerkan infiltration run for a hydrologically relevant soil hydraulic characterization. J. Hydrol., 584, 12469714. DOI: 10.1016/j.jhydrol.2020.124697

Bagarello, V., David, S.M., 2020. Run duration effects on the hydrodynamic properties of a loam soil estimated by steadystate infiltration methods. Journal of Agricultural Engineering, 51, 4, 229-238. DOI:10.4081/jae.2020.1075

Bagarello, V., Sgroi, A., 2007. Using the simplified falling head technique to detect temporal changes in field-saturated hydraulic conductivity at the surface of a sandy loam soil. Soil Till. Res., 94, 283-294.

Bagarello, V., Di Prima, S., Iovino, M., 2014. Comparing alternative algorithms to analyze the beerkan infiltration experiment. Soil Sci. Soc. Am. J., 78, 724-736. DOI: 10.2136/sssaj2013.06.0231

Braud, I., De Condappa, D., Soria, J.M., Haverkamp, R., Angulo-Jaramillo, R., Galle, S., Vauclin, M., 2005. Use of scaled forms of the infiltration equation for the estimation of unsaturated soil hydraulic properties (the Beerkan method). Eur. J. Soil Sci., 56, 361-374.

Cislerova, M., Simunek, J., Vogel, T., 1988. Changes of steadystate infiltration rates in recurrent ponding infiltration experiments. J. Hydrol., 104, 1-16.

Concialdi, P., Di Prima, S., Bhanderi, H.M., Stewart, R.D., Abou Najm, M.R., Lal Gaur, M., Angulo-Jaramillo, R., Lassabatere, L., 2020. An open-source instrumentation package for intensive soil hydraulic characterization. J. Hydrol., 582, 124492. DOI: 10.1016/j.jhydrol.2019.124492

Di Prima, S., 2015. Automated single ring infiltrometer with a low-cost microcontroller circuit. Comput. Electron. Agr., 118, 390-395.

Di Prima, S., Lassabatere, L., Bagarello, V., Iovino, M., Angulo-Jaramillo, R., 2016. Testing a new automated single ring infiltrometer for Beerkan infiltration experiments. Geoderma 262, 20-34. DOI: 10.1016/j.geoderma.2015.08.006

Di Prima, S., Concialdi, P., Lassabatere, L., Angulo-Jaramillo, R., Pirastru, M., Cerdà, A., Keesstra, S., 2018. Laboratory testing of Beerkan infiltration experiments for assessing the role of soil sealing on water infiltration. Catena, 167, 373384. DOI: 10.1016/j.catena.2018.05.013

Di Prima, S., Stewart, R.D., Castellini, M., Bagarello, V., Abou Najm, M.R., Pirastru, M., Giadrossich, F., Iovino, M., Angulo-Jaramillo, R., Lassabatere, L., 2020. Estimating the macroscopic capillary length from Beerkan infiltration experiments and its impact on saturated soil hydraulic conductivity predictions. J. Hydrol., 589, 125159. DOI: 10.1016/j.jhydrol.2020.125159

Dohnal, M., Vogel, T., Dusek, J., Votrubova, J., Tesar, M., 2016. Interpretation of ponded infiltration data using numerical experiments. J. Hydrol. Hydromech., 64, 3, 289299.

Dušek, J., Dohnal, M., Vogel, T., 2009. Numerical analysis of ponded infiltration experiment under different experimental conditions. Soil Water Res., 4, S22-S27.

Elrick, D.E., Reynolds, W.D., 1992a. Infiltration from constant- head well permeameters and infiltrometers. In: Topp, G.C., Reynolds, W.D., Green, R.E. (Eds.): Advances in measurement of soil physical properties: Bringing theory into practice (SSSA special publication no. 30, pp. 1-24). Madison: Soil Science Society of America, Inc.

Elrick, D.E., Reynolds, W.D., 1992b. Methods for analyzing constant-head well permeameter data. Soil Sci. Soc. Am. J., 56, 320-323.

Haverkamp, R., Ross, P.J., Smettem, K.R.J., Parlange, J.Y., 1994. Three-dimensional analysis of infiltration from the disc infiltrometer. 2. Physically-based infiltration equation. Water Resour. Res., 30, 2931-2935.

Iovino, M., Castellini, M., Bagarello, V., Giordano, G., 2016. Using static and dynamic indicators to evaluate soil physical quality in a Sicilian area. Land Degrad. Dev., 27, 200-210. DOI: $10.1002 /$ ldr.2263

Iovino, M., Angulo-Jaramillo, R., Bagarello, V., Gerke, H.H., Jabro, J., Lassabatere, L., 2017. Thematic Issue on Soil Water Infiltration. J. Hydrol. Hydromech., 65, 3, 205-208. DOI: 10.1515/johh-2017-0036

Lassabatere, L., Angulo-Jaramillo, R., Soria Ugalde, J.M., Cuenca, R., Braud, I., Haverkamp, R. 2006. Beerkan estimation of soil transfer parameters through infiltration experiments -BEST. Soil Sci. Soc. Am. J., 70, 2, 521-535. DOI: 10.2136/sssaj2005.0026

Lassabatere, L., Di Prima, S., Bouarafa, S., Iovino, M., Bagarello, V., Angulo-Jaramillo, R., 2019a. BEST-2K method for characterizing dual-permeability unsaturated soils with ponded and tension infiltrometers. Vadose Zone J., 18, 180124. DOI: 10.2136/vzj2018.06.0124

Lassabatere, L., Di Prima, S., Angulo-Jaramillo, R., Keesstra, S., Salesa, D., 2019b. Beerkan multi-runs for characterizing water infiltration and spatial variability of soil hydraulic properties across scales. Hydrolog. Sci. J., 64, 2, 165-178. DOI: 10.1080/02626667.2018.1560448

Lassabatere, L., Yilmaz, D., Peyrard, X., Peyneau, P.E., Lenoir, T., Šimůnek, J., Angulo-Jaramillo, R., 2014. New analytical model for cumulative infiltration into dual-permeability soils. Vadose Zone Journal, 13, 1-15. DOI: 10.2136/vzj2013.10.0181

Lee, D.M., Reynolds, W.D., Elrick, D.E., Clothier, B.E., 1985. A comparison of three field methods for measuring saturated hydraulic conductivity. Can. J. Soil Sci., 65, 563-573.

Lilliefors, H.W., 1967. On the Kolmogorov-Smirnov test for normality with mean and variance unknown. J. Am. Stat. Assoc., 62, 318, 399-402.

Mubarak, I., Mailhol, J.C., Angulo-Jaramillo, R., Ruelle, P., Boivin, P., Khaledian, M., 2009. Temporal variability in soil hydraulic properties under drip irrigation. Geoderma, 150, $158-165$.

Ndiaye, B., Esteves, M., Vandervaere, J.-P., Lapetite, J.-M., Vauclin, M., 2005. Effect of rainfall and tillage direction on the evolution of surface crusts, soil hydraulic properties and runoff generation for a sandy loam soil. J. Hydrol., 307, 1-4, 294-311. DOI: $10.1016 /$ j.jhydrol.2004.10.016

Picciafuoco, T., Morbidelli, R., Flammini, A., Saltalippi, C., Corradini, C., Strauss, P., Blöschl, G., 2019. On the estimation of spatially representative plot scale saturated hydraulic conductivity in an agricultural setting. J. Hydrol., 570, 106117. DOI: 10.1016/j.jhydrol.2018.12.044

Reynolds, W.D., Elrick, D.E., 1990. Ponded infiltration from a single ring: I. Analysis of steady flow. Soil Sci. Soc. Am. J., 54, 1233-1241.

Reynolds, W.D., Gregorich, E.G., Curnoe, W.E., 1995. Characterisation of water transmission properties in tilled and 
untilled soils using tension infiltrometers. Soil Till. Res., 33, 2, 117-131.

Reynolds, W.D., Bowman, B.T., Brunke, R.R., Drury, C.F., Tan, C.S., 2000. Comparison of tension infiltrometer, pressure infiltrometer, and soil core estimates of saturated hydraulic conductivity. Soil Sci. Soc. Am. J., 64, 478-484. DOI: $10.2136 /$ sssaj2000.642478x

Smith, R.E., 1999. Technical note: Rapid measurement of soil sorptivity. Soil Sci. Soc. Am. J., 63, 55-57.

Souza, E.S., Antonino, A.C.D., Heck, R.J., Montenegro, S.M.G.L, Lima, J.R.S., Sampaio, E.V.S.B., AnguloJaramillo, R. Vauclin, M., 2014. Effect of crusting on the physical and hydraulic properties of a soil cropped with Castor bean (Ricinus Communis L.) in the northeastern region of Brasil. Soil Till. Res., 141, 55-61. DOI: 10.1016/j.still.2014.04. 004

Touma, J., Voltz, M., Albergel, J., 2007. Determining soil saturated hydraulic conductivity and sorptivity from single ring infiltration tests. Eur. J. Soil Sci., 58, 1, 229-238. DOI: 10.1111/j.1365-2389.2006.00830.x
Verbist, K.M.J., Cornelis, W.M., Torfs, S., Gabriels, D., 2013. Comparing methods to determine hydraulic conductivities on stony soils. Soil Sci. Soc. Am. J., 77, 25-42. DOI: 10.2136/sssaj2012.0025

White, I., Sully, M.J., 1987. Macroscopic and microscopic capillary length and time scales from field infiltration. Water Resour. Res., 23, 1514-1522.

White, I., Sully, M.J., Melville, M.D., 1989. Use and hydrological robustness of time-to-incipient-ponding. Soil Sci. Soc. Am. J., 53, 1343-1346.

Wu, L., Pan, L., Roberson, M.J., Shouse, P.J., 1997. Numerical evaluation of ring-infiltrometers under various soil conditions. Soil Sci., 162, 11, 771-777.

Yilmaz, D., Lassabatere, L., Angulo-Jaramillo, R., Deneele, D., Legret, M., 2010. Hydrodynamic characterization of basic oxygen furnace slag through an adapted BEST method. Vadose Zone J., 9, 107. DOI: 10.2136/vzj2009.0039

Received 13 February 2021 Accepted 13 April 2021 